September, 2020

Hurnal Grouper, Vol 11 (2) : 11-17

P-ISSN 2086 - 8480 / E-ISSN 2716-2702

\title{
Strategi Pemasaran Gelondongan Udang Vannamei (Litopenaeus vannamei) Di Kabupaten Lamongan
}

\section{Marketing Strategy of White Shrimp (Litopenaeus vannamei) in Lamongan District}

\author{
Norma Aprilia Fanni1 $^{*}$, Endah Sih Prihatini ${ }^{1}$, Moh. Azus Syarof ${ }^{1}$ \\ ${ }^{1}$ Fakultas Perikanan Universitas Islam Lamongan, Jl. Veteran, No. 53 A Lamongan \\ *Corresponding Author: normaaprilia@unisla.ac.id
}

\begin{abstract}
ABSTRAK
Udang vaname (Litopenaeus vannamei) merupakan salah satu sumberdaya hayati perairan bernilai ekonomis penting dan telah dibudidayakan secara komersial adalah pada penerapan teknologi sederhana sampai intensif dalam produksi udang vaname di wilayah tropis telah menunjukkan bahwa udang vanamei memiliki keunggulan dibandingkan dengan jenis udang yang lain. Tujuan dari penelitian ini adalah untuk mengetahui strategi pemasaran gelondongan udang vaname yang diterapkan oleh pengusaha udang vaname di Kabupaten Lamongan (yang dilaksanakan di Kecamatan Glagah dan Kecamatan Deket). Jenis penelitian ini adalah kualitatif dengan teknik pengumpulan data yang digunakan yaitu data primer dan data sekunder. Metode penelitian ini menggunakan studi kasus (case study). Analisis data yang digunakan dalam penelitian ini analisis deskriptif (akumulasi atas data dasar dalam cara deskriptif semata-mata tidak perlu mencari atau menerangkan saling berhubungan, menguji hipotesis, membuat peramalan, atau mendapatkan makna atau implikasi) kemudian di analisis menggunakan analisis SWOT untuk mengevaluasi kekuatan dan kelemahan, peluang dan ancaman dalam suatu usaha, baik yang sedang berlangsung maupun dalam perencanaan baru. Hasil penelitian ini menunjukkan bahwa berdasarkan perhitungan matriks SWOT posisi. Strategi untuk pengembangan gelondongan udang vaname di Kabupaten Lamongan berada pada kuadran I yaitu menggunakan Strategi Agresif dimana pengusaha memiliki kekuatan dan peluang yang besar. Jadi di harapkan pengusaha harus lebih meningkatkan usahanya sehingga bisa mencapai peluang dan bisa menambah kekuatan dari usahanya.
\end{abstract}

Kata kunci: strategi pemasaran, analisis SWOT, udang vaname.

\begin{abstract}
Vaname shrimp (Litopenaeus vannamei) is one of the important economically valuable aquatic resources and has been commercially cultivated. The application of simple to intensive technology in vaname shrimp production in the tropics has shown that vanamei shrimp has an advantage compared to other types of shrimp. The purpose of this study was to determine the marketing strategy of vaname shrimps implemented by vanameshrimps entrepreneurs in Lamongan District (which was carried out in Glagah District and Deket District). This type of research is qualitative data collection techniques used are primary data and secondary data. This research method uses a case study. Analysis of the data used in this research is descriptive analysis (the accumulation of basic data in a descriptive way does not only need to look for or explain interconnectedness, test hypotheses, make predictions, or obtain meaning or implications) then analyzed using SWOT analysis to evaluate the strengths and weaknesses, opportunities and threats in a business, both ongoing and in new planning. The results of this study indicate that based on SWOT matrix position calculations. The strategy for developing vaname shrimps in Lamongan Regency is in quadrant I, namely using an Aggressive Strategy where entrepreneurs have great strength and opportunities. So it is expected that entrepreneurs should further improve their business so they can achieve opportunities and can add strength to their business.
\end{abstract}

Keywords: marketing strategy, SWOT analysis, vaname shrimp. 


\section{PENDAHULUAN}

Udang vaname (Litopenaeus vannamei) merupakan salah satu sumberdaya hayati perairan bernilai ekonomis penting dan telah dibudidayakan secara komersial adalah pada penerapan teknologi sederhana sampai intensif dalam produksi udang vaname di wilayah tropis telah menunjukkan bahwa udang vaname memiliki keunggulan dibandingkan dengan jenis udang yang lain. Udang vaname pertumbuhannya lebih cepat, dapat mengisi semua kolom air sehingga dapat dibudidayakan dengan padat tebar yang tinggi, bersifat eurihalin, serta lebih tahan terhadap penyakit dan gangguan lingkungan (Poernomo, 2004 dalam Widodo dkk., 2011).

Potensi perikanan di Kabupaten Lamongan cukup besar yang meliputi sector perikanan tangkap, perikanan budidaya dan sektor usaha perikanan lainnya. Produksi perikanan tangkap rata-rata 40.000 ton/tahun dengan nilai $\leq 160$ milyar dan jumlah nelayan sebanyak 23.807 orang. Sedangkan pada sub sektor perikanan budidaya, kegiatan diusahakan pada areal sekitar 25.3222 hektar, meliputi tambak (1.380 ha), sawah tambak (23.602 ha) dan kolam (340 ha). Produksi perikanan budidaya rata-rata $42.346,963$ ton/tahun pada tahun 2014 dengan nilaisebesar 554 milyar yang diusahakan oleh 159.440 orang atau 28.701 RTP (Disperikla, 2013 dalam Yuniarti dan Maizar, 2018).

Pembenihan merupakan suatu kegiatan untuk menghasilkan benih yang menjadi input bagi kegiatan pembesaran atau budidaya(Ana, 2009). Proses pembenihan biasanya dilakukan pada pembenihan (hatchery) udang komersial yakni dengan cara pemijahan secara alami untuk menghasilkan larva.

Pembesaran/ budidaya udang vaname disawah tambak awalnya didahului dengan tahapan penggelondongan atau pentokolan, yakni melakukan aklimatisasi benih yang dihasilkan dari hecthery yang mulanya air dengan salinitas diatas $30 \mathrm{ppt}$ menjadi salinitas 5 ppt. Caranya dengan menurunkan salinitas air asin setiap hari sebanyak 3 ppt dengan menambahkan air tawar sebanyak $10-15 \mathrm{~cm}$.

Permintaan pembudidaya dalam jenis udang ini sangatlah besarbaik dipasar local maupun internasional, karena jenis udang ini memiliki keunggulan pada nilai gizi yang sangat tinggi serta memiliki nilai ekonomis cukup tinggi sehingga menyebabkan pesatny abudidaya udang vaname di berbagai daerah. Selama satu tahun pembudidaya udang vaname mampu melakukan budidaya sebanyak 3 kali masa panen. Itu artinya, pembudidaya didaerah penelitian lebih cepat dan lebih sering memperoleh penghasilan dalam satu tahun.

Pentokolan udang vaname adalah suatu proses perawatan atau pemeliharaan dari naupli sampai ke post larva dengan cara aklimatisasi selama $\leq 5-7$ hari. Setelah itu benih udang vaname dapat dibesarkan atau di budidayakan ditambak.

Di Kabupaten Lamongan terdapat banyak usaha budidaya gelondongan udang vanname, sehingga perlu dilakukan penelitian untuk mengetahui apakah strategi pemasaran yang digunakan oleh petani termasuk dalam pengusaha yang memiliki kekuatan dan peluang yang besar.

\section{METODE PENELITIAN}

Penelitian ini dilaksanakan di Kabupaten Lamongan dengan penentuan pengambilan sampel di tiga lokasi pentokolan udang vaname yang memiliki kesamaan dalam proses dan cara perlakuan yaitu di Kecamatan Glagah, dan Kecamatan Deket.

Metode yang digunakan dalam penelitian ini yakni metode studi kasus (case study), yaitu suatu bentuk penelitian yang ditujukan untuk mendiskripsikan atau menggambarkan fenomena-fenomena yang ada, baik fenomena alamiah atau fenomena yang direkayasa manusia (Sukmadinata, 2002 dalam Prakoso dkk., 2016).

Analisis data yang digunakan dalam penelitian ini adalah analisis deskriptif, yaitu akumulasi atas data dasar dalam cara deskriptif semata-mata tidak perlu mencari atau menerangkan saling berhubungan, menguji hipotesis, membuat peramalan, atau mendapatkan makna atau implikasi, walaupun penelitian yang bertujuan untuk menemukan halhal tersebut dapat mencakup juga metodemetode deskriptif. Kemudian dianalisis dengan 
analisis SWOT dengan langkah-langkah sebagai berikut (Effendi dkk., 2017) :

1. Pembobotan serta Pemberian Rating pada Matriks IFE dan EFE

2. Penentuan Matriks IE

3. Matriks SWOT

\section{HASIL DAN PEMBAHASAN}

\section{Analisis SWOT untuk Strategi Pemasaran Gelondongan Udang Vaname}

\section{A. Matriks Faktor Strategi Internal (IFAS)}

Matriks ini menyajikan rangkuman dan evaluasi kekuatan dan kelemahan dalam berbagai bidang terhadap usaha. Hasil matriks faktor strategi internal (IFAS) dapat dilihat pada Tabel 1.

\section{B. Matriks Faktor Strategi Eksternal (EFAS)}

Matriks ini menyajikan rangkuman dan evaluasi peluang dan ancaman dalam berbagai bidang terhadap usaha. Hasil matriks faktor strategi eksternal (EFAS) dapat dilihat pada Tabel 2.

Dari Tabel 1 dan Tabel 2 dapat dijelaskan bahwa:

1. Jumlah dari skor pembobotan pada peluang yaitu 1,08 bawah dari kekuatan yaitu 1,22 sehingga dapat menciptakan strategi yang menggunakan kekuatan untuk memperoleh peluang. Kekuatan yang ada pada usaha gelondongan udang vaname harus dilakukan secara maksimal agar dapat memperoleh peluang yang ada.

2. Jumlah skor pembobotan pada kekuatan lebih besar dari ancaman yaitu kekuatan 1,22 sedangkan ancaman 1,02 sehingga dapat menciptakan strategi yang menggunakan kekuatan untuk mengatasi ancaman. Kekuatan usaha gelondongan udang vaname harus lebih dimaksimalkan agar dapat mengantisipasi ancaman yang ada.

3. Jumlah dari skor pembobotan pada kelemahan lebih rendah dari peluang yaitu kelemahan 1,04 sedangkan peluang 1,08 sehingga dapat meciptakan strategi pada peluang yang mampu meminimalkan kelemahan, peluang yang ada harus dimanfaatkan semaksimal mungkin agar dapat menutupi kelemahan yang ada pada usaha gelondongan udang vaname.

4. Jumlah dari skor pembobotan pada kelemahan hampir sama dengan ancaman yaitu 1,04 dan 1,02 maka pengusaha harus lebih defensif dalam usahanya untuk meminimalkan jumlah ancaman dan kelemahan agar usahanya dapat berkembang.

Tabel 1. Internal Strategic Faktors Summary) (IFAS) Penentuan Faktor-Faktor Internal Lingkungan (Kekuatan dan Kelemahan).

\begin{tabular}{clccc}
\hline No. & \multicolumn{1}{c}{ Faktor Internal } & Bobot & Rating & Skor \\
\hline A. & KEKUATAN & & & \\
1 & Lokasi yang strategis & 0,11 & 2 & 0,22 \\
2 & Sarana dan perasarana & 0,11 & 2 & 0,22 \\
3 & Keramahan pemilik usaha & 0,12 & 3 & 0,36 \\
4 & Naupli udang diambil dari hacthery yang & 0,11 & 2 & 0,22 \\
& berkualitas & & & \\
5 & Kualitas benih yang bagus & 0,10 & 2 & 0,2 \\
\hline & & & Jumlah skor & 1,22 \\
\hline B. & KELEMAHAN & 0,09 & 2 & 0,18 \\
1 & Banyaknya biaya operasional & 0,11 & 3 & 0,33 \\
2 & Tidak adanya karyawan ahli & 0,10 & 3 & 0,3 \\
3 & Tidak adanya struktur organisasi & 0,07 & 1 & 0,07 \\
4 & Tidak adanya kegiatan promosi & 0,08 & 2 & 0,16 \\
5 & Kurangnya biaya promosi & & Jumlah skor & 1,04 \\
\hline & & 1,00 & & 2,26
\end{tabular}


Selisi IFAS

0.18

Tabel 2. EFAS (Eksternal Strategic FaktorSumarry) Penentuan Faktor-Faktor Eksternal Lingkungan (Peluang dan Ancaman)

\begin{tabular}{clccc}
\hline No & \multicolumn{1}{c}{ Faktor Eksternal } & Bobot & Rating & Skor \\
\hline A. & PELUANG & & & \\
1 & Permintaan konsumen yang terus meningkat & 0,10 & 2 & 0,2 \\
2 & Benih yang diminati usaha petambak & 0,11 & 2 & 0,22 \\
3 & Peluang pasar yang besar & 0,11 & 2 & 0,22 \\
4 & Harga jual tinggi & 0,11 & 2 & 0,22 \\
5 & Kesediaan naupli yang banyak & 0,11 & 2 & 0,22 \\
\hline Jumlahskor & & & 1,08 \\
\hline B. & ANCAMAN & & & \\
1 & Banyak pesaing & 0.12 & 3 & 0,36 \\
2 & Usaha yang mudah ditiru & 0,09 & 2 & 0,18 \\
3 & Adanya penyakit dan bakteri yang menyerang & 0,08 & 2 & 0,16 \\
& benih udang vaname & & & 0,16 \\
4 & Persaingan pasar dengan usaha lain & 0,08 & 2 & 0,16 \\
5 & Isu penghitungan benih kurang akurat & 0,08 & 2 & 1,02 \\
\hline & $\quad$ & Jumlah skor \\
& Total EFAS & 0,99 & & 2,1 \\
& Selisi EFAS & & & \\
\hline
\end{tabular}

C. Tahap Analisis Matriks IFAS dan Matriks EFAS

Model analisis matriks IFAS dan Matriks EFAS tersebut adalah Matriks SWOT sehingga dapat memunculkan beberapa kategori yakni strategi SO, strategi ST, strategi WO, strategi WT (Tabel 3).

Strategi yang muncul dari Tabel 3 dapat menjadi acuan dalam memperbaiki strategi pengembangan usaha pentokolan udang vaname, adapun yang di maksud adalah :

a. Strategi $S O$

Strategi ini dibuat berdasarkan jalan pikiran perusahaan, yaitu dengan memanfaatkan seluruh kekuatan untuk merebut dan memanfaatkan peluang sebesarbesarnya. Alternatif strategi yang di rekomendasikan kepada perusahaan yaitu:

1. Memperbanyak produksi benih.

2. Meningkatkan kualiatas benih.

b. Strategi $S T$

Strategi ini adalah strategi dalam menggunaan kekuatan yang dimiliki perusahaan untuk mengatasi ancaman. Adapun beberapa alternatif strategi yang di rekomendasikan kepada perusahaan yaitu :
1. Mengambil sempel kantong dan memberikan kepada pembeli untuk menghitung sampel.

2. Memanage/ memelihara benih udang vaname dengan bagus.

c. Strategi $W O$

Strategi diterapkan berdasarkan pemanfaatan peluang yang ada dengan cara meminimalkan kelemahan yang ada. Berikut beberapa alternatif strategi yang di rekomendasikan kepada perusahaan yaitu:

1. Merekrut karyawan tenaga ahli untuk meningkatkan efektifitas produksi.

2. Meningkatkan kegiatan promosi.

\section{d. Strategi WT}

Strategi ini didasarkan pada kegiatan yang bersifat defensif dan berusaha meminimalkan kelemahan yang ada serta menghindari ancaman. Adapun beberapa alternatif strategi yang di rekomendasikan kepada perusahaan yaitu :

1. Mengambil karyawan ahli agar meminimalisir adanya penyakit.

2. Membuat kegiatan rutin untuk promosi dengan biaya (modal) secukupnya dan diatur dengan efektif dan efisien. 
Tabel 3. Matriks SWOT

\begin{tabular}{|c|c|c|}
\hline $\begin{array}{l}\text { Faktor } \\
\text { Eksternal }\end{array}$ & $\begin{array}{l}\qquad \text { Strength (S) } \\
\text { 1. Lokasi yang strategis } \\
\text { 2. Sarana dan prasarana } \\
\text { 3. Keramahan pemilik usaha } \\
\text { 4. Naupli udang diambil dari } \\
\text { hacthery yang berkualitas } \\
\text { 5. Kualitas benih yang bagus }\end{array}$ & $\begin{array}{l}\text { Weakness }(\mathbf{W}) \\
\text { 1. Banyaknya biaya operasional } \\
\text { 2. Tidak adanya karyawan ahli } \\
\text { 3. Tidak adanya struktur } \\
\text { organisasi } \\
\text { 4. Tidak adanya kegiatan } \\
\text { promosi } \\
\text { 5. Kurangnya biaya promosi }\end{array}$ \\
\hline Opportunity (O) & Strategi (SO) & Strategi (WO) \\
\hline $\begin{array}{l}\text { 1. Permintaan konsumen yang } \\
\text { terus meningkat } \\
\text { 2. Benih yang diminati usaha } \\
\text { petambak } \\
\text { 3. Peluang pasar yang besar } \\
\text { 4. Harga jual tinggi } \\
\text { 5. Kesediaan naupli yang } \\
\text { banyak }\end{array}$ & $\begin{array}{l}\text { 1. Memperbanyak produksi } \\
\text { benih (S: } 5 \text { / O: } 1,3) \\
\text { 2. Meningkatkan kualiatas } \\
\text { benih (S: } 4 \text { / O: 2) }\end{array}$ & $\begin{array}{l}\text { 1. Merekrut karyawan tenaga } \\
\text { ahli untuk meningkatkan } \\
\text { efektifitas produksi (W: } 2 \text { / O: } \\
\text { 2, 5) } \\
\text { 2. Meningkatkan } \\
\text { promosi (W: } 3,4 / \text { ogiatan } \\
1,2,3,4,5)\end{array}$ \\
\hline Treaths $(T)$ & Strategi (ST) & Strategi (WT) \\
\hline $\begin{array}{l}\text { 1. Banyaknya pesaing } \\
\text { 2. Usaha yang mudah ditiru } \\
\text { 3. Adanya penyakit dan bakteri } \\
\text { yang menyerang benih udang } \\
\text { vaname } \\
\text { 4. Persaingan pasar dengan } \\
\text { usaha lain } \\
\text { 5. Isu penghitungan benih } \\
\text { kurang akurat }\end{array}$ & $\begin{array}{l}\text { 1. Mengambilkan sempel } \\
\text { kantong dan memberikan } \\
\text { kepada pembeli untuk } \\
\text { menghitung sampel (S: } 3 \text { / T: } \\
\text { 5) } \\
\text { 2. Memanage/ memelihara } \\
\text { benih udang vannamei } \\
\text { dengan bagus (S: } 4 \text { / T: } 3 \text { ) }\end{array}$ & $\begin{array}{l}\text { 1. Mengambil karyawan ahli } \\
\text { agar meminimalisir adanya } \\
\text { penyakit (W: } 2 / \mathrm{T}: 3) \\
\text { 2. Membuat kegiatan rutin } \\
\text { untuk promosi dengan biaya } \\
\text { (modal) secukupnya dan } \\
\text { diatur dengan efektif dan } \\
\text { efisien (W: 4,5/T: } 1 \text { ) }\end{array}$ \\
\hline
\end{tabular}

Berdasarkan Kuadran SWOT, posisi titik koordinat berada pada kuadran 1 yaitu menggunakan Strategi Agresif dimana perusahaan memiliki kekuatan dan peluang yang besar (Gambar 1). Jadi diharapkan pengusaha harus lebih meningkatkan usahanya sehingga dapat memanfaatkan peluang dengan maksimal dan dapat menambah kekuatan dari usahanya. Jika pengusaha dapat lebih agresif maka dapat dipastikan usaha tersebut akan semakin berkembang sehingga mendapatkan keuntungan dengan maksimal. 


\section{Kuadran SWOT}

$\mathrm{O}$

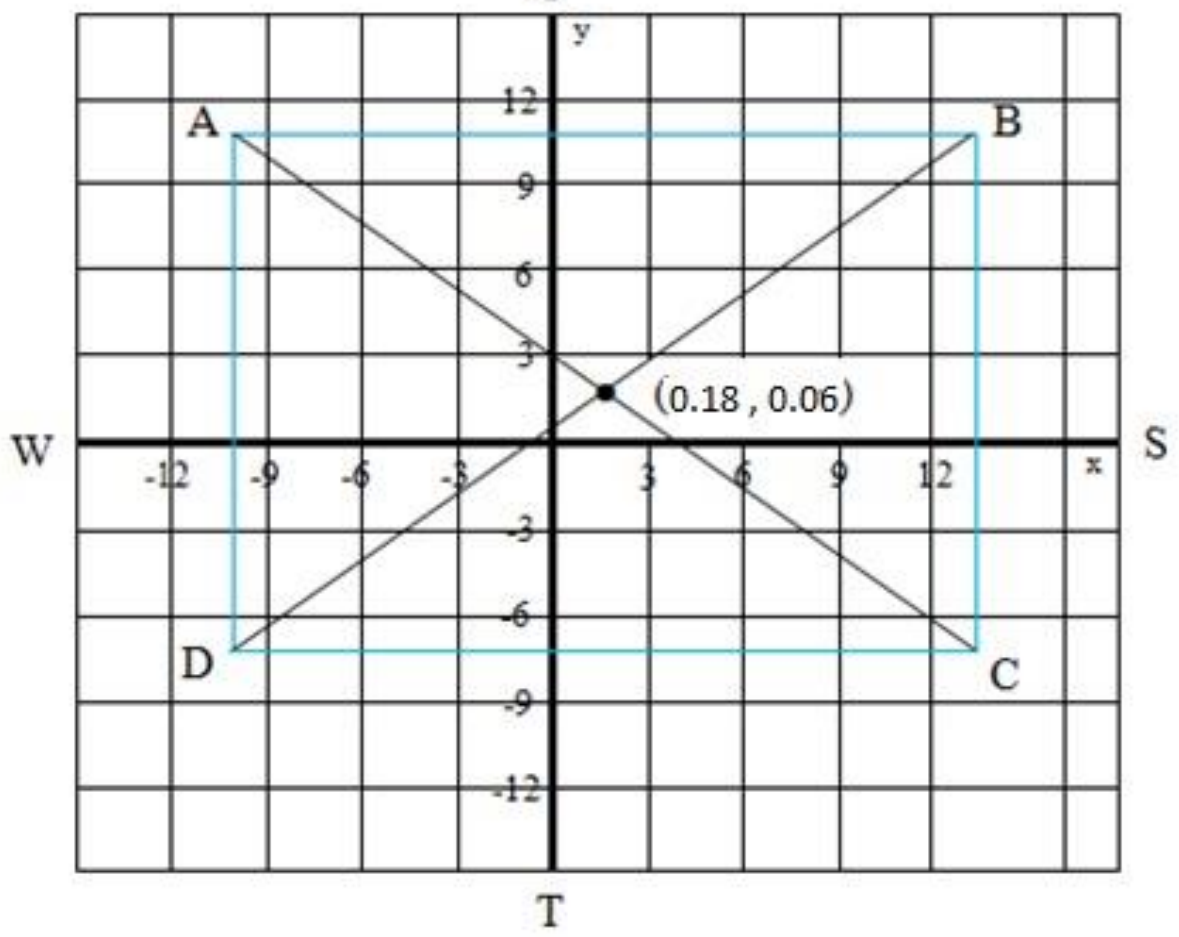

Gambar 1. Kuadran SWOT

\section{KESIMPULAN}

Berdasarkan perhitungan matriks SWOT posisi, strategi untuk pemasaran gelondongan udang vaname di Kabupaten Lamongan berada pada kuadran I yaitu menggunakan Strategi Agresif dimana pengusaha memiliki kekuatan dan peluang yang besar. Strategi yang digunakan adalah strategi SO, dan dalam strategi ini ada dua macam cara yang di hasilkan dari penelitian yaitu memperbanyak produksi benih dan meningkatkan kualiatas benih.

\section{UCAPAN TERIMA KASIH}

Penulis mengucapkan terima kasih kepada pemilik pentokolan udang vaname di Kecamatan Glagah dan Kecamatan Deket serta semua pihak yang terlibat dalam penelitian.

\section{DAFTAR PUSTAKA}

Effendi, U., R. Astuti, R., \& Melati, D. D. (2017).Strategi Pengembagan Usaha Coklat Menggunakan Quantitative Strategic Planning Matrix (QSPM) dan Multi Attribute Utility Theory (MAUT) di Kampung Coklat, Blitar. Jurnal Teknologi dan Manajemen Agroindustri, 6(1), 31-40.

Prakoso, A. A., Elfitasari, T \& Basuki, F. (2016). Studi Analisa Usaha dan Prospek Pengembangan Budidaya Udang Vannamei (Litopenaeus vannamei) Sistem Intensif di Kecamatan Sluke, Kabupaten Rembang. Seminar Nasional Tahunan Ke V Hasil-Hasil Penelitian Perikanan dan Kelautan. (pp. 311-331).

Widodo, A. F., Pantjara, B., Adhiyudanto, N. B \& Rachmansyah. (2011). Performansi Fisiologis Udang Vaname, Litopenaeus 
September, 2020

Furnal Grouper, Vol 11 (2) : 11-17

P-ISSN 2086 - 8480 / E-ISSN 2716-2702

vannamei Yang Dipelihara Pada Media Air Tawar Dengan Aplikasi Kalium. $J$. Ris. Akuakultur,6(2), 225-241.

Yuniarti, A \& Maizar, A. S. (2018). Peningkatan Produksi Ikan Pada Sistem Sawah
Tambak Di Desa Rayung Gumuk

Glagah Lamongan. Journal Of Innovation And Applied Technology, 4(1), 576-580. 